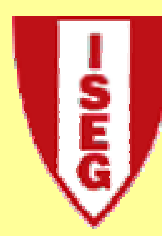

School of Economics and Management

TECHNICAL UNIVERSITY OF LISBON

Department of Economics

Maria Rosa Borges

Efficient Market Hypothesis in European Stock Markets

WP 20/2008/DE/CIEF

Working Papers

ISSN N0 0874-4548

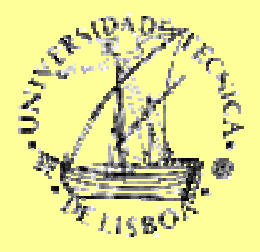




\section{Efficient Market Hypothesis in European Stock Markets}

MARIA ROSA BORges

Technical University of Lisbon

Instituto Superior de Economia e Gestão

Department of Economics

Rua Miguel Lupi, 20, 1249-078 Lisbon

e-mail: mrborges@iseg.utl.pt

Draft Version: April 2008 


\title{
Efficient Market Hypothesis in European Stock Markets
}

\begin{abstract}
This paper reports the results of tests on the weak-form market efficiency applied to stock market indexes of France, Germany, UK, Greece, Portugal and Spain, from January 1993 to December 2007. We use a serial correlation test, a runs test, an augmented Dickey-Fuller test and the multiple variance ratio test proposed by Lo and MacKinlay (1988) for the hypothesis that the stock market index follows a random walk. The tests are performed using daily and monthly data for the whole period and for the period of the last five years, i.e., 2003 to 2007. Overall, we find convincing evidence that monthly prices and returns follow random walks in all six countries. Daily returns are not normally distributed, because they are negatively skewed and leptokurtic. France, Germany, UK and Spain meet most of the criteria for a random walk behavior with daily data, but that hypothesis is rejected for Greece and Portugal, due to serial positive correlation. However, the empirical tests show that these two countries have also been approaching a random walk behavior after 2003. (JEL G14; G15)
\end{abstract}

\section{Introduction}

Efficient market theory and the random walk hypothesis have been major issues in financial literature, for the past thirty years. While a random walk does not imply that a market can not be exploited by insider traders, it does imply that excess returns are not obtainable through the use of information contained in the past movement of prices. The validity of the random walk hypothesis has important implications for financial theories and investment strategies, and so this issue is relevant for academicians, investors and regulatory authorities. Academicians seek to understand the behavior of stock prices, and standard riskreturn models, such as the capital asset pricing model, depend of the hypotheses of normality or random walk behavior of prices. For investors, trading strategies have to be designed taking into account if the prices are characterized by random walks or by persistence in the short run, and mean reversion in the long run. Finally, if a stock market is not efficient, the pricing mechanism does not ensure the efficient allocation of capital within an economy, with 
negative effects for the overall economy. Evidence of inefficiency may lead regulatory authorities to take the necessary steps and reforms to correct it.

Since the seminal work of Fama (1970), several studies show that stock price returns do not follow a random walk and are not normally distributed, including Fama and French (1988) and Lo and MacKinlay (1988), among many others. The globalization markets spawned interest on the study of this issue, with many studies both on individual markets and regional markets, such as Latin America (Urrutia 1995, Grieb and Reyes 1999), Africa (Smith at al. 2002, Magnusson and Wydick 2002), Asia (Huang 1995, Groenewold and Ariff 1998), Middle East (Abraham et al. 2002) and Europe (Worthington and Higgs 2004), several reporting unconformity with random walk behavior. The list is too extensive for a comprehensive survey, which is beyond the purpose of this study.

Recent studies of weak-form efficiency of European markets include Smith and Ryoo (2003) and Worthington and Higgs (2004). Smith and Ryoo (2003) use a variance ratio test on weekly data for five European indexes, covering April 1991 to August 1998, and reject the random walk hypothesis for Greece, Hungary, Poland and Portugal but find that Turkey follows a random walk.

Worthington and Higgs (2004) conduct a very detailed study of twenty European countries, from August 1995 to May 2003, applying multiple testing procedures, including serial correlation test, runs test, augmented Dickey Fuller test and a variance ratio test. They find that all indexes are not well explained by the normal distribution, and only five countries meet the most stringent criteria for a random walk, namely, Germany, Ireland, Portugal, Sweden and the United Kingdom, while France, Finland, the Netherlands, Norway and Spain meet only some of the requirements for a random walk.

The main contribution of this paper is to add to international evidence on the random walk theory of stock market prices, by testing six stock market indexes, the first three from Western European developed markets (France, Germany and UK) and the other three from 
Southern European less developed capital markets (Greece, Portugal and Spain), with very recent data, up until December 2007. The first three countries are included also as a control for the quality of the data and of the tests, as we would expect, ex-ante, for the empirical evidence to be more favorable to the random walk hypothesis in those countries' markets. We follow the Worthington and Higgs (2004) approach of using several different tests, to avoid that a spurious result from one of the tests might affect our conclusions. We will look at the global results of all four tests, to draw our conclusions.

\section{Methodology}

\section{Serial correlation of returns}

An intuitive test of the random walk for an individual time series is to check for serial correlation. If the stock market indexes returns exhibit a random walk, the returns are uncorrelated at all leads and lags. We perform least square regressions of daily and monthly returns on lags one to ten of the return series. To test the joint hypothesis that all serial coefficients $\rho(t)$ are simultaneously equal to zero, we apply the Box-Pierce $Q$ statistic:

$$
Q_{B P}=n \sum_{t=1}^{m} \hat{\rho}(t)
$$

where $Q_{B P}$ is asymptotically distributed as a chi-square with $m$ degrees of freedom, $n$ is the number of observations, and $m$ is the maximum lag considered (in this study, $m$ equals ten). We also use a Ljung-Box test, which provides a better fit to the chi-square distribution, for small samples:

$$
Q_{L B}=n(n+2) \sum_{t=1}^{m} \frac{\hat{\rho}^{2}(t)}{n-t}
$$




\section{Runs test}

To test for serial independence in the returns we also employ a runs test, which determines whether successive price changes are independent of each other, as should happen under the null hypothesis of a random walk. By observing the number of runs, that is, the successive price changes (or returns) with the same sign, in a sequence of successive price changes (or returns), we can test that null hypothesis. We consider two approaches: in the first, we define as a positive return (+) any return greater than zero, and a negative return (-) if it is below zero; in the second approach, we classify each return according to its position with respect to the mean return of the period under analysis. In this last approach, we have a positive (+) each time the return is above the mean return and a negative (-) if it is below the mean return. This second approach has the advantage of allowing for and correcting the effect of an eventual time drift in the series of returns. Note that this is a non-parametric test, which does not require the returns to be normally distributed. The runs test is based on the premise that if price changes (returns) are random, the actual number of runs $(R)$ should be close to the expected number of runs $\left(\mu_{R}\right)$.

Let $n_{+}$and $n_{-}$be the number of positive returns $(+)$and negative returns (-) in a sample with $n$ observations, where $n=n_{+}+n_{-}$. For large sample sizes, the test statistic is approximately normally distributed:

$$
Z=\frac{R-\mu_{R}}{\sigma_{R}} \approx N(0,1)
$$

where $\mu_{R}=\frac{2 n_{+} n_{-}}{n}+1$ and $\sigma_{R}=\sqrt{\frac{2 n_{+} n_{-}\left(2 n_{+} n_{-}-n\right)}{n^{2}(n-1)}}$. 


\section{Unit Root Tests}

Our third test is the augmented Dickey-Fuller (ADF) test which is used to test the existence of a unit root in the series of price changes in the stock index series, by estimating the following equation through OLS:

$$
\Delta P_{t}=\alpha_{0}+\alpha_{1} t+\rho_{0} P_{t-1}+\sum_{i=1}^{q} \rho_{i} \Delta P_{i t-i}+\varepsilon_{i t}
$$

where $P_{t}$ is the price at time $t$, and $\Delta P_{t}=P_{t}-P_{t-1}, \rho_{i}$ are coefficients to be estimated, $q$ is the number of lagged terms, $t$ is the trend term, $\alpha_{i}$ is the estimated coefficient for the trend, $\alpha_{0}$ is the constant, and $\varepsilon$ is white noise. The null hypothesis of a random walk is $H_{0}: \rho_{0}=0$ and its alternative hypothesis is $H_{1}: \rho_{0} \neq 0$. Failing to reject $H_{0}$ implies that we do not reject that the time series has the properties of a random walk. We use the critical values of MacKinnon (1994) in order to determine the significance of the $t$-statistic associated with $\rho_{0}$.

\section{Variance Ratio Tests}

An important property of the random walk is explored by our final test, the variance ratio test. If $P_{t}$ is a random walk, the ratio of the variance of the $q^{\text {th }}$ difference scaled by $q$ to the variance of the first difference tends to equal one, that is, the variance of the $q$-differences increases linearly in the observation interval,

$$
V R(q)=\frac{\sigma^{2}(q)}{\sigma^{2}(1)}
$$

where $\sigma^{2}(q)$ is $1 / q$ the variance of the $q$-differences and $\sigma^{2}(1)$ is the variance of the first differences. Under the null hypothesis $V R(q)$ must approach unity. The following formulas are taken from Lo and MacKinlay [1988], who propose this specification test, for a sample size of $n q+1$ observations $\left(P_{0}, P_{1}, \ldots, P_{n q}\right)$ : 


$$
\sigma^{2}(q)=\frac{1}{m} \sum_{t=q}^{n q}\left(P_{t}-P_{t-q}-q \hat{\mu}\right)^{2}
$$

where $m=q(n q-q+1)\left(1-\frac{q}{n q}\right)$ and $\hat{\mu}$ is the sample mean of $\left(P_{t}-P_{t-1}\right): \hat{\mu}=\frac{1}{n q}\left(P_{n q}-P_{0}\right)$ and

$$
\sigma^{2}(1)=\frac{1}{(n q-1)} \sum_{t=1}^{n q}\left(P_{t}-P_{t-1}-\hat{\mu}\right)^{2}
$$

Lo and MacKinlay (1988) generate the asymptotic distribution of the estimated variance ratios and propose two test statistics, $Z(q)$ and $Z^{*}(q)$, under the null hypothesis of homoskedastic increments random walk and heteroskedastic increments random walk respectively. If the null hypothesis is true, the associated test statistic has an asymptotic standard normal distribution. Assuming homoskedastic increments, we have

$$
Z(q)=\frac{V R(q)-1}{\phi_{o}(q)} \approx N(0,1)
$$

where $\phi_{o}(q)=\left[\frac{2(2 q-1)(q-1)}{3 q(n q)}\right]^{1 / 2}$. Assuming heteroskedastic increments, the test statistic is

$$
Z^{*}(q)=\frac{V R(q)-1}{\phi_{e}(q)} \approx N(0,1)
$$

where $\phi_{e}(q)=\left[4 \sum_{t=1}^{q-1}\left(1-\frac{t}{q}\right) \hat{\delta}_{t}\right]^{1 / 2}$ and $\hat{\delta}_{t}=\frac{\sum_{j=t+1}^{n q}\left(P_{j}-P_{j-1}-\hat{\mu}\right)^{2}\left(P_{j-t}-P_{j-t-1}-\hat{\mu}\right)^{2}}{\left[\sum_{j=1}^{n q}\left(P_{j}-P_{j-1}-\hat{\mu}\right)^{2}\right]^{2}}$.

which is robust under heteroskedasticity, hence can be used for a longer time series analysis. The procedure proposed by Lo and MacKinlay (1988) is devised to test individual variance ratio tests for a specific $q$-difference, but under the random walk hypothesis, we must have $\operatorname{VR}(q)=1$ for all $q$. A multiple variance ratio test is proposed by Chow and Denning (1993). Consider a set of $m$ variance ratio tests $\left\{M_{r}\left(q_{i}\right) \mid i=1,2, \ldots, m\right\}$ where $M_{r}(q)=V R(q)-1$, 
associated with the set of aggregation intervals $\left\{q_{i} \mid i=1,2, \ldots, m\right\}$. Under the random walk hypothesis, there are multiple sub-hypotheses:

$$
\begin{aligned}
& H_{0 i}: M_{r}\left(q_{i}\right)=0 \text { for } i=1,2, \ldots, m \\
& H_{1 i}: M_{r}\left(q_{i}\right) \neq 0 \text { for any } i=1,2, \ldots, m
\end{aligned}
$$

The rejection of any or more $H_{0 i}$ rejects the random walk null hypothesis. In order to facilitate comparison of this study with previous research (Lo and MacKinlay, 1988 and Campbell et al. 1997) on other markets, the $q$ is selected as $2,4,8$, and 16 . For a set of test statistics $\left\{Z\left(q_{i}\right) \mid i=1,2, \ldots, m\right\}$, the random walk hypothesis is rejected if any one of the $\operatorname{VR}\left(q_{i}\right)$ is significantly different than one, so only the maximum absolute value in the set of test statistics is considered. The Chow and Denning (1993) multiple variance ratio test is based on the result:

$$
P R\left\{\max \left(\left|Z\left(q_{1}\right)\right|, \ldots,\left|Z\left(q_{m}\right)\right|\right) \leq \operatorname{SMM}(\alpha ; m ; T)\right\} \geq 1-\alpha
$$

in which $\operatorname{SMM}(\alpha ; m ; T)$ is the upper $\alpha$ point of the Studentized Maximum Modulus (SMM) distribution with parameters $m$ and $T$ (sample size) degrees of freedom. Asymptotically,

$$
\lim _{T \rightarrow \infty} \operatorname{SMM}(\alpha ; m ; \infty)=Z_{\alpha^{*} / 2}
$$

where $Z_{\alpha^{*} / 2}$ is standard normal with $\alpha^{*}=1-(1-\alpha)^{1 / m}$. Chow and Denning (1993) control the size of the multiple variance ratio test by comparing the calculated values of the standardized test statistics, either $Z(q)$ or $Z^{*}(q)$ with the $S M M$ critical values. If the maximum absolute value of, say, $Z(q)$ is greater than the critical value at a predetermined significance level then the random walk hypothesis is rejected. 


\section{The Data}

Our data are daily closing values of stock market indexes for France, Germany, UK, Greece, Portugal and Spain ${ }^{*}$, chosen as representative for each of these markets. The source of all data is Reuters, and it includes observations from 1 January 1993 to 31 December 2007, during which the markets were very volatile, especially in the case of Greece, as shown visually in Figure 1.

FIGURE 1

Stock Market Indexes - Closing Prices - 1993 to 2007

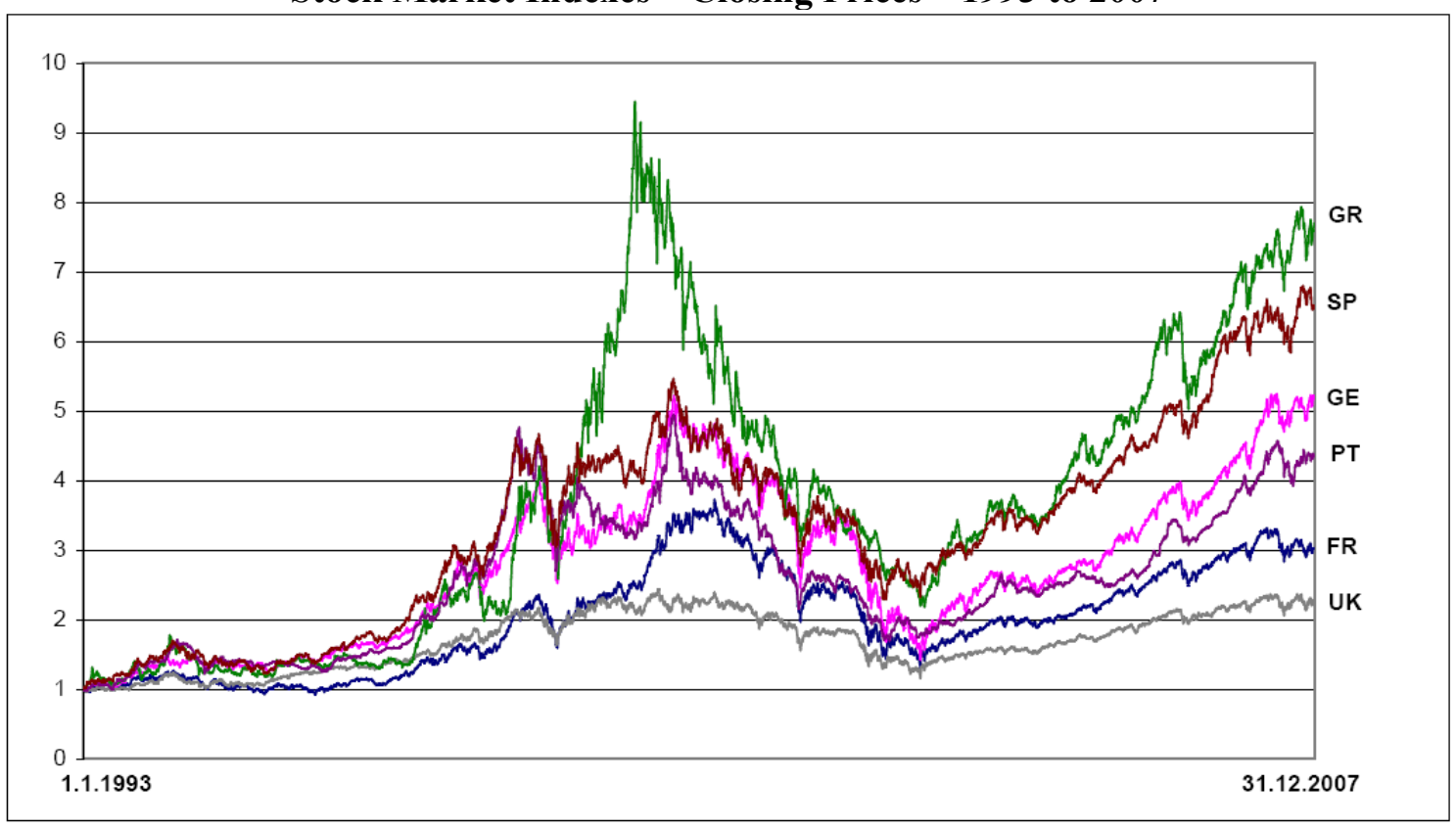

We apply the empirical tests to the whole 15 -year period, but also to a smaller period of five years, from 1 January 2003 to 31 December 2007. The testing of different periods has the advantage of allowing for structural changes, so that the market may follow a random walk in some period while in other periods that hypothesis may be rejected. A similar approach of arbitrarily-chosen periods is taken by Wheeler et al. (2002) in their analysis of the

\footnotetext{
* The stock market indexes are, respectively, CAC 40, DAX 30, FTSE 100, ATHEX General Index, PSI 20 and IBEX 35.
} 
Warsaw Stock Exchange. We are particularly interested in examining the last five years, from

January 2003 to December 2007, because it has not been covered by previous studies.

We use the daily closing prices to compute monthly data. For the monthly price series,

we use the observations of day 15 of each month. In case of a missing observation on day 15 ,

we use day 14. If day 14 is missing, we use day 16. If day 16 is missing we use day 13 , and so

on. From country samples of around 3880 daily observations, we generate 180 monthly

observations for the whole period. The returns are computed as the logarithmic difference

between two consecutive prices in a series. Table 1 shows the descriptive statistics for the returns of the stock market indexes.

TABLE 1

Descriptive statistics for the returns of the stock market indexes: January 1993 to December 2007

\begin{tabular}{|c|c|c|c|c|c|c|c|c|c|c|c|c|}
\hline & $\begin{array}{c}\begin{array}{c}\text { France } \\
1993-2007\end{array} \\
\end{array}$ & $\begin{array}{c}\text { Germany } \\
1993-2007 \\
\end{array}$ & $\begin{array}{c}\text { UK } \\
1993-2007 \\
\end{array}$ & $\begin{array}{c}\text { Greece } \\
1993-2007 \\
\end{array}$ & $\begin{array}{c}\text { Portugal } \\
1993-2007 \\
\end{array}$ & $\begin{array}{c}\text { Spain } \\
\text { 1993-2007 } \\
\end{array}$ & $\begin{array}{c}\begin{array}{c}\text { France } \\
\text { 2003-2007 }\end{array} \\
\end{array}$ & $\begin{array}{r}\text { Germany } \\
\text { 2003-2007 } \\
\end{array}$ & $\begin{array}{c}\text { UK } \\
\text { 2003-2007 } \\
\end{array}$ & $\begin{array}{c}\begin{array}{c}\text { Greece } \\
\text { 2003-2007 }\end{array} \\
\end{array}$ & $\begin{array}{c}\begin{array}{c}\text { Portugal } \\
\text { 2003-2007 }\end{array} \\
\end{array}$ & $\begin{array}{c}\begin{array}{c}\text { Spain } \\
\text { 2003-2007 }\end{array} \\
\end{array}$ \\
\hline \multicolumn{13}{|c|}{ Daily Returns } \\
\hline Observations & 3878 & 3878 & 3878 & 3878 & 3878 & 3878 & 1292 & 1292 & 1292 & 1292 & 1292 & 1292 \\
\hline Mean return & 0,0003 & 0,0004 & 0,0002 & 0,0005 & 0,0004 & 0,0005 & 0,0005 & 0,0008 & 0,0004 & 0,0008 & 0,0006 & 0,0007 \\
\hline Annual. return & 0,0739 & 0,1124 & 0,0542 & 0,1406 & 0,0992 & 0,1279 & 0,1243 & 0,2194 & 0,1003 & 0,2337 & 0,1683 & 0,1953 \\
\hline Maximum & 0,0700 & 0,0755 & 0,0590 & 0,0766 & 0,0694 & 0,0632 & 0,0700 & 0,0709 & 0,0590 & 0,0497 & 0,0384 & 0,0405 \\
\hline Minimum & $-0,0768$ & $-0,0887$ & $-0,0589$ & $-0,0962$ & $-0,0959$ & $-0,0734$ & $-0,0583$ & $-0,0634$ & $-0,0492$ & $-0,0611$ & $-0,0463$ & $-0,0424$ \\
\hline St. Deviation & 0,0130 & 0,0141 & 0,0103 & 0,0152 & 0,0097 & 0,0126 & 0,0107 & 0,0120 & 0,0089 & 0,0103 & 0,0068 & 0,0094 \\
\hline Studentiz. range & 11,3143 & 11,6754 & 11,4814 & 11,3651 & 17,0475 & 10,8074 & 11,9752 & 11,1596 & 12,1673 & 10,8023 & 12,3821 & 8,8507 \\
\hline Skewness & $-0,1068$ & $-0,2685$ & $-0,2145$ & $-0,1102$ & $-0,6442$ & $-0,2104$ & $-0,0588$ & $-0,0461$ & $-0,1375$ & $-0,3197$ & $-0,3690$ & $-0,3115$ \\
\hline Excess Kurtosis & 2,8273 & 3,6514 & 3,1670 & 4,3767 & 8,2305 & 3,0243 & 3,8577 & 3,9134 & 4,0828 & 2,5914 & 3,8434 & 2,3142 \\
\hline Jarque-Bera & $1299 * *$ & $2201 * *$ & $1650^{* *}$ & $3103 * *$ & $11214 * *$ & $1506^{* *}$ & $801,9 * *$ & $824,9 * *$ & $901,4 * *$ & $383,5^{* *}$ & $824,5^{* *}$ & $309,2 * *$ \\
\hline JB p-value & 0,0000 & 0,0000 & 0,0000 & 0,0000 & 0,0000 & 0,0000 & 0,0000 & 0,0000 & 0,0000 & 0,0000 & 0,0000 & 0,0000 \\
\hline \multicolumn{13}{|c|}{ Monthly Returns } \\
\hline Observations & 179 & 179 & 179 & 179 & 179 & 179 & 60 & 60 & 60 & 60 & 60 & 60 \\
\hline Mean return & 0,0063 & 0,0092 & 0,0047 & 0,0111 & 0,0084 & 0,0102 & 0,0100 & 0,0158 & 0,0083 & 0,0172 & 0,0134 & 0,0156 \\
\hline Annual. return & 0,0778 & 0,1155 & 0,0577 & 0,1415 & 0,1050 & 0,1293 & 0,1268 & 0,2072 & 0,1048 & 0,2265 & 0,1736 & 0,2037 \\
\hline Maximum & 0,1350 & 0,1649 & 0,1008 & 0,4198 & 0,1695 & 0,1526 & 0,0715 & 0,1649 & 0,0838 & 0,1194 & 0,0797 & 0,1053 \\
\hline Minimum & $-0,2327$ & $-0,2817$ & $-0,1478$ & $-0,2578$ & $-0,2040$ & $-0,2361$ & $-0,1169$ & $-0,1312$ & $-0,0948$ & $-0,1441$ & $-0,0759$ & $-0,0948$ \\
\hline St. Deviation & 0,0507 & 0,0588 & 0,0413 & 0,0846 & 0,0558 & 0,0574 & 0,0365 & 0,0498 & 0,0311 & 0,0511 & 0,0354 & 0,0426 \\
\hline Studentiz. range & 7,2540 & 7,6017 & 6,0175 & 8,0123 & 6,6992 & 6,7679 & 5,1658 & 5,9479 & 5,7455 & 5,1521 & 4,3926 & 4,6972 \\
\hline Skewness & $-1,0511$ & $-1,0124$ & $-0,8951$ & 0,4718 & $-0,3887$ & $-0,7244$ & $-1,3417$ & $-0,5157$ & $-0,7291$ & $-0,7719$ & $-0,6215$ & $-0,2976$ \\
\hline Excess Kurtosis & 2,8865 & 3,1355 & 2,0670 & 3,0764 & 1,2182 & 2,1915 & 2,7620 & 1,6616 & 1,7221 & 0,8207 & $-0,1467$ & $-0,0729$ \\
\hline Jarque-Bera & $95,10^{* *}$ & $103,9 * *$ & $55,77 * *$ & $77,22 * *$ & $15,58^{* *}$ & $51,47 * *$ & $37,07 * *$ & $9,56 * *$ & $12,73^{* *}$ & $7,642 *$ & 3,917 & 0,899 \\
\hline JB p-value & 0,0000 & 0,0000 & 0,0000 & 0,0000 & 0,0004 & 0,0000 & 0,0000 & 0,0084 & 0,0017 & 0,0219 & 0,1411 & 0,6380 \\
\hline
\end{tabular}

Notes: The Jarque-Bera test is a goodness-of-fit measure of departure from normality, based on the sample kurtosis and skewness, and is distributed as a chi-squared with two degrees of freedom. The null hypothesis is a joint hypothesis of both the skewness and excess kurtosis being 0 , since samples from a normal distribution have an expected skewness of 0 and an expected excess kurtosis of 0 . As the definition of $J B$ shows, any deviation from this increases the JB statistic.

* Null hypothesis rejection significant at the $5 \%$ level. ** Null hypothesis rejection significant at the $1 \%$ level.

The daily returns are negatively skewed in all six countries both for the period 1993-

2007 and for the sub-period 2003-2007, which means that large negative returns tend to be larger than the higher positive returns. The level of excess kurtosis is positive for all countries, 
in both periods, indicating that the distributions of returns are leptokurtic, thus having higher peaks than would be expected from normal distributions. The only exceptions are Portugal and Spain, in the last five year period, with a negative excess kurtosis. The Jarque-Bera statistic rejects the hypothesis of a normal distribution of daily returns in all countries and periods, at a significance level of $1 \%$, although this statistic is lower for all countries in the period 2003-2007.

For the period 1993-2007, the evidence from monthly returns is consistent with the evidence from daily returns, showing negative skewness and positive excess kurtosis, and a rejection of normality by the Jarque-Bera statistic. Note, however, that this statistic is much closer to zero than in the case of daily returns, thus evidencing a milder departure from the normal distribution. In the last five years, the departure from normality is further reduced for all countries, and in the case of Portugal and Spain we can no longer reject that monthly returns follow a normal distribution.

\section{Results}

\section{Serial Correlation}

The results for the tests on serial correlation, Box-Pierce and Ljung-Box statistics are presented in Table 2, for daily and monthly returns.

The evidence of positive serial correlation of lag 1 of daily returns is only present in Greece and Portugal, both for the whole period and for the last five years, which is inconsistent with the random walk hypothesis. However, the coefficients of 0.14 and 0.15 , which we find for these two countries in the whole sample, are lower in the last five years, 0.07 and 0.06. All other countries do not show positive serial correlation, as most lag coefficients are not statistically significant different from zero and, when they are significant, they have negative signs, indicating a tendency for reversion to the mean. Taken together, we 
cannot reject the joint significance of the coefficients for lags 1 to 10 , except in the case of

France, and also Greece and Spain, for the last five years period.

TABLE 2

Serial correlation coefficients and Q-statistics for Returns of the stock market indexes: January 1993 to December 2007

\begin{tabular}{|c|c|c|c|c|c|c|c|c|c|c|c|c|}
\hline & $\begin{array}{c}\text { France } \\
\text { 1993-2007 }\end{array}$ & $\begin{array}{c}\text { Germany } \\
1993-2007 \\
\end{array}$ & $\begin{array}{c}\text { UK } \\
1993-2007 \\
\end{array}$ & $\begin{array}{c}\text { Greece } \\
1993-2007 \\
\end{array}$ & $\begin{array}{c}\text { Portugal } \\
1993-2007 \\
\end{array}$ & $\begin{array}{c}\text { Spain } \\
1993-2007 \\
\end{array}$ & $\begin{array}{c}\begin{array}{c}\text { France } \\
\text { 2003-2007 }\end{array} \\
\end{array}$ & $\begin{array}{c}\text { Germany } \\
2003-2007 \\
\end{array}$ & $\begin{array}{c}\text { UK } \\
\text { 2003-2007 } \\
\end{array}$ & $\begin{array}{c}\begin{array}{c}\text { Greece } \\
\text { 2003-2007 }\end{array} \\
\end{array}$ & $\begin{array}{c}\text { Portugal } \\
\text { 2003-2007 } \\
\end{array}$ & $\begin{array}{c}\text { Spain } \\
\text { 2003-2007 }\end{array}$ \\
\hline \multicolumn{13}{|c|}{ Daily Returns } \\
\hline Observations & 3868 & 3868 & 3868 & 3868 & 3868 & 3868 & 1282 & 1282 & 1282 & 1282 & 1282 & 1282 \\
\hline $\begin{array}{l}\text { Lag } 1 \\
\text { Lag } 2 \\
\text { Lag } 3 \\
\text { Lag } 4 \\
\text { Lag } 5 \\
\text { Lag } 6 \\
\text { Lag } 7 \\
\text { Lag } 8 \\
\text { Lag } 9 \\
\text { Lag } 10 \\
\end{array}$ & $\begin{array}{c}-0,010 \\
-0,001 \\
-0,026 \\
0,001 \\
-0,014 \\
-0,003 \\
-0,021 \\
0,016 \\
-0,017 \\
-0,006 \\
\end{array}$ & $\begin{array}{c}-0,019 \\
-0,008 \\
-0,015 \\
0,010 \\
-0,028 \\
-0,044^{* *} \\
-0,004 \\
0,025 \\
-0,004 \\
-0,026 \\
\end{array}$ & $\begin{array}{c}-0,010 \\
-0,041^{*} \\
-0,068^{* *} \\
0,004 \\
-0,046^{* *} \\
-0,038^{*} \\
-0,015 \\
0,035^{*} \\
0,012 \\
-0,043^{* *} \\
\end{array}$ & $\begin{array}{c}0,143^{* *} \\
-0,020 \\
0,000 \\
-0,005 \\
0,004 \\
0,020 \\
-0,019 \\
0,026 \\
-0,016 \\
0,004 \\
\end{array}$ & $\begin{array}{c}0,151^{* *} \\
-0,002 \\
0,020 \\
0,037^{*} \\
-0,012 \\
-0,016 \\
0,025 \\
0,041^{*} \\
-0,020 \\
0,046^{* *} \\
\end{array}$ & $\begin{array}{c}0,035^{*} \\
-0,037^{*} \\
-0,029 \\
0,008 \\
-0,005 \\
-0,022 \\
0,004 \\
0,029 \\
-0,008 \\
0,032^{*} \\
\end{array}$ & $\begin{array}{c}-0,025 \\
0,010 \\
-0,017 \\
0,001 \\
-0,004 \\
0,006 \\
-0,023 \\
0,014 \\
-0,024 \\
-0,004 \\
\end{array}$ & $\begin{array}{c}-0,057^{*} \\
0,045 \\
0,004 \\
-0,015 \\
-0,077^{*} * \\
-0,039 \\
-0,092^{*} * \\
0,053 \\
-0,019 \\
-0,053 \\
\end{array}$ & $\begin{array}{c}-0,102^{* *} \\
0,024 \\
-0,044 \\
0,005 \\
-0,057^{*} \\
-0,019 \\
-0,111^{*} * \\
-0,012 \\
0,008 \\
-0,046 \\
\end{array}$ & $\begin{array}{c}0,071^{*} \\
0,006 \\
0,005 \\
0,003 \\
-0,008 \\
0,024 \\
-0,029 \\
0,020 \\
-0,028 \\
0,006 \\
\end{array}$ & $\begin{array}{c}0,063^{*} \\
0,010 \\
0,030 \\
0,031 \\
-0,058^{*} \\
0,009 \\
0,044 \\
0,032 \\
-0,072^{* *} \\
0,068^{*} \\
\end{array}$ & $\begin{array}{c}-0,036 \\
0,017 \\
-0,022 \\
0,016 \\
-0,009 \\
-0,034 \\
-0,072 * \\
0,043 \\
-0,033 \\
-0,050 \\
\end{array}$ \\
\hline $\begin{array}{l}\text { Box-Pierce Stat. } \\
p \text {-value } \\
\text { Ljung-Box Stat. } \\
p \text {-value }\end{array}$ & $\begin{array}{c}7,72 \\
0,656 \\
7,74 \\
0,655 \\
\end{array}$ & $\begin{array}{c}18,64^{*} \\
0,045 \\
18,68^{*} \\
0,045 \\
\end{array}$ & $\begin{array}{c}52,01 * * \\
0,000 \\
52,11^{* *} \\
0,000 \\
\end{array}$ & $\begin{array}{c}87,20 * * \\
0,000 \\
87,28 * * \\
0,000 \\
\end{array}$ & $\begin{array}{c}114,8 * * \\
0,000 \\
114,9 * * \\
0,000 \\
\end{array}$ & $\begin{array}{c}22,87^{*} \\
0,011 \\
22,91^{*} \\
0,011 \\
\end{array}$ & $\begin{array}{c}3,07 \\
0,980 \\
3,08 \\
0,979 \\
\end{array}$ & $\begin{array}{c}35,41 * * \\
0,000 \\
35,62 * * \\
0,000 \\
\end{array}$ & $\begin{array}{c}40,24 * * \\
0,000 \\
40,45^{* *} \\
0,000 \\
\end{array}$ & $\begin{array}{c}9,91 \\
0,448 \\
9,95 \\
0,445 \\
\end{array}$ & $\begin{array}{c}28,40 * * \\
0,002 \\
28,59 * * \\
0,001 \\
\end{array}$ & $\begin{array}{l}18,04 \\
0,054 \\
18,16 \\
0,052 \\
\end{array}$ \\
\hline \multicolumn{13}{|c|}{ Monthly Returns } \\
\hline Observations & 169 & 169 & 169 & 169 & 169 & 169 & 50 & 50 & 50 & 50 & 50 & 50 \\
\hline $\begin{array}{l}\text { Lag } 1 \\
\text { Lag } 2 \\
\text { Lag } 3 \\
\text { Lag } 4 \\
\text { Lag } 5 \\
\text { Lag } 6 \\
\text { Lag } 7 \\
\text { Lag } 8 \\
\text { Lag } 9 \\
\text { Lag } 10 \\
\end{array}$ & $\begin{array}{c}0,075 \\
0,087 \\
0,077 \\
-0,136 \\
0,093 \\
0,024 \\
-0,049 \\
-0,029 \\
0,232 * * \\
0,010 \\
\end{array}$ & $\begin{array}{c}0,098 \\
0,094 \\
0,003 \\
-0,064 \\
0,111 \\
0,011 \\
-0,093 \\
-0,011 \\
0,174 * \\
-0,071 \\
\end{array}$ & $\begin{array}{c}-0,107 \\
0,046 \\
0,006 \\
-0,054 \\
0,082 \\
-0,009 \\
0,004 \\
-0,018 \\
0,149 \\
0,011 \\
\end{array}$ & $\begin{array}{c}0,043 \\
0,068 \\
0,113 \\
-0,026 \\
-0,133 \\
-0,066 \\
0,184^{*} \\
0,044 \\
0,096 \\
-0,086 \\
\end{array}$ & $\begin{array}{c}0,224 * * \\
-0,019 \\
0,062 \\
-0,043 \\
0,000 \\
0,018 \\
0,047 \\
-0,044 \\
0,069 \\
0,043 \\
\end{array}$ & $\begin{array}{c}0,046 \\
-0,030 \\
0,055 \\
-0,019 \\
-0,058 \\
-0,053 \\
0,087 \\
-0,035 \\
0,157^{*} \\
0,032 \\
\end{array}$ & $\begin{array}{c}0,050 \\
-0,145 \\
-0,056 \\
-0,378^{*} \\
0,433^{*} \\
-0,249 \\
-0,140 \\
0,062 \\
0,226 \\
-0,309 \\
\end{array}$ & $\begin{array}{c}-0,048 \\
-0,035 \\
-0,092 \\
-0,367^{*} \\
0,267 \\
-0,145 \\
-0,105 \\
-0,074 \\
0,079 \\
-0,260^{*} \\
\end{array}$ & $\begin{array}{c}-0,136 \\
-0,304 \\
-0,180 \\
-0,289 \\
0,106 \\
-0,176 \\
-0,196 \\
0,121 \\
0,026 \\
-0,105 \\
\end{array}$ & $\begin{array}{c}0,088 \\
-0,309^{*} \\
0,010 \\
-0,377^{*} \\
-0,053 \\
-0,185 \\
-0,234 \\
-0,087 \\
0,085 \\
-0,277 \\
\end{array}$ & $\begin{array}{c}0,255 \\
-0,198 \\
-0,158 \\
-0,104 \\
0,052 \\
-0,178 \\
-0,104 \\
-0,068 \\
-0,011 \\
-0,071 \\
\end{array}$ & $\begin{array}{c}-0,245 \\
0,023 \\
-0,161 \\
-0,462 * \\
-0,123 \\
-0,025 \\
-0,105 \\
-0,059 \\
-0,083 \\
-0,079 \\
\end{array}$ \\
\hline $\begin{array}{l}\text { Box-Pierce Stat. } \\
p \text {-value } \\
\text { Ljung-Box Stat. } \\
p \text {-value }\end{array}$ & $\begin{array}{c}17,54 \\
0,063 \\
18,46^{*} \\
0,048 \\
\end{array}$ & $\begin{array}{l}13,34 \\
0,205 \\
14,01 \\
0,172 \\
\end{array}$ & $\begin{array}{c}7,77 \\
0,651 \\
8,14 \\
0,615\end{array}$ & $\begin{array}{l}15,97 \\
0,100 \\
16,77 \\
0,080 \\
\end{array}$ & $\begin{array}{l}11,38 \\
0,328 \\
11,69 \\
0,306\end{array}$ & $\begin{array}{c}7,96 \\
0,633 \\
8,42 \\
0,588\end{array}$ & $\begin{array}{c}29,45^{* *} \\
0,001 \\
34,89 * * \\
0,000\end{array}$ & $\begin{array}{c}16,50 \\
0,086 \\
19,47^{*} \\
0,035\end{array}$ & $\begin{array}{c}16,69 \\
0,082 \\
18,97^{*} \\
0,041 \\
\end{array}$ & $\begin{array}{c}21,43^{*} \\
0,018 \\
25,01 * * \\
0,005\end{array}$ & $\begin{array}{c}9,75 \\
0,463 \\
10,87 \\
0,368\end{array}$ & $\begin{array}{c}17,17 \\
0,071 \\
19,35^{*} \\
0,036\end{array}$ \\
\hline
\end{tabular}

Notes: Both the Box-Pierce statistic and the Ljung-Box statistic test the null hypothesis of overall zero serial correlation coefficients for lags 1 through 10, and are distributed as a chi-square distribution with ten degrees of freedom. For small samples, the Ljung-Box statistic provides a finite-sample correction that yields a better fit to the chi-square distribution.

* Null hypothesis rejection significant at the $5 \%$ level. ** Null hypothesis rejection significant at the $1 \%$ level.

The evidence of serial correlation decays as the lag length increases, and it virtually disappears for the monthly data. This means that the larger the interval of the observations of prices, the less important is the lagged price for explaining future prices. This is consistent with the findings of several other studies including Fama (1965), Panas (1990) and Ma and Barnes (2001). Again, the exception is Portugal, with a very high lag 1 coefficient, of 0.22 , which remains high in the last five years, but in this last case it is not statistically significant. 
Another interesting aspect of the data is that four countries show negative serial correlation in the lag of 4 months, when we consider only the behavior in the last five years.

Taken together, the evidence from this test tends to refute more strongly the random walk hypothesis only in Greece and Portugal, due to the presence of positive serial correlation in lag 1 . However, we should be cautious in the interpretation of these results, as they assume normality, which we have shown that is not a valid assumption for the distribution of daily and monthly returns of all six stock market indexes, in the period 1993 to 2007.

\section{Runs Test}

The results of the runs test, which do not depend on normality of returns, are presented in Table 3, for daily and monthly returns.

Considering the period 1993-2007, the number of runs is significant less than the expected number of runs both for Portugal and Greece, using daily returns which is consistent with a positive serial correlation of returns and clearly rejecting the random walk hypothesis. For Portugal this hypothesis is also rejected using monthly returns. The random walk hypothesis is not rejected for France, Germany, UK and Spain, using either daily or monthly returns. In fact, the number of runs even exceeds the expected number of runs in the case of France, in the daily data.

In the more recent period of five years, between 2003 and 2007, the daily data for France refutes the random walk hypothesis, but in this case because the number of runs clearly exceeds the number of runs we would expect to find, if prices followed a random walk. The UK, Germany and Spain also show more runs than expected, but this only significant for these last two countries. Greece shows again less runs than expected, more noticeably when returns are defined relatively to the mean return. The daily data does not allow the rejection of the random walk hypothesis in Portugal, but this the only country where the evidence is mixed, when using monthly returns. For all other countries, monthly returns in 
the last five years are compatible with a random walk. The only country where the null

hypothesis is never rejected by the runs test is the UK.

TABLE 3

Runs tests for daily and monthly returns of the stock markets indexes: January 1993 to December 2007

\begin{tabular}{|c|c|c|c|c|c|c|c|c|c|c|c|c|}
\hline & $\begin{array}{c}\text { France } \\
1993-2007 \\
\end{array}$ & $\begin{array}{c}\text { Germany } \\
1993-2007 \\
\end{array}$ & $\begin{array}{c}\text { UK } \\
1993-2007 \\
\end{array}$ & $\begin{array}{c}\text { Greece } \\
1993-2007 \\
\end{array}$ & $\begin{array}{c}\text { Portugal } \\
1993-2007 \\
\end{array}$ & $\begin{array}{c}\text { Spain } \\
1993-2007\end{array}$ & $\begin{array}{c}\text { France } \\
\text { 2003-2007 }\end{array}$ & $\begin{array}{c}\text { Germany } \\
2003-2007 \\
\end{array}$ & $\begin{array}{c}\text { UK } \\
\text { 2003-2007 } \\
\end{array}$ & $\begin{array}{c}\text { Greece } \\
2003-2007 \\
\end{array}$ & $\begin{array}{c}\begin{array}{c}\text { Portugal } \\
\text { 2003-2007 }\end{array} \\
\end{array}$ & $\begin{array}{c}\text { Spain } \\
2003-2007\end{array}$ \\
\hline \multicolumn{13}{|c|}{ Panel A: positive/negative daily returns defined relative to zero } \\
\hline$n_{+}$ & 2050 & 2146 & 2080 & 2069 & 2114 & 2159 & 692 & 731 & 709 & 742 & 727 & 744 \\
\hline$n$ & 1828 & 1732 & 1798 & 1809 & 1764 & 1719 & 599 & 560 & 582 & 549 & 564 & 547 \\
\hline$R$ & 1953 & 1914 & 1920 & 1704 & 1733 & 1891 & 700 & 661 & 670 & 601 & 620 & 673 \\
\hline$\mu_{R}$ & 1933,6 & 1917,9 & 1929,7 & 1931,3 & 1924,2 & 1915,0 & 643,2 & 635,2 & 640,3 & 632,1 & 636,2 & 631,5 \\
\hline$\sigma_{R}$ & 31,031 & 30,778 & 30,968 & 30,993 & 30,879 & 30,732 & 17,865 & 17,643 & 17,784 & 17,557 & 17,672 & 17,540 \\
\hline Z & 0,624 & $-0,127$ & $-0,315$ & $-7,333 * *$ & $-6,192 * *$ & $-0,782$ & $3,182 * *$ & 1,464 & 1,673 & $-1,770$ & $-0,917$ & $2,368 *$ \\
\hline$p$-value & 0,533 & 0,899 & 0,753 & 0,000 & 0,000 & 0,434 & 0,001 & 0,143 & 0,094 & 0,077 & 0,359 & 0,018 \\
\hline \multicolumn{13}{|c|}{ Panel B: positive/negative daily returns defined relative to the mean return } \\
\hline$n_{+}$ & 1930 & 1994 & 1937 & 1847 & 1887 & 1962 & 658 & 665 & 656 & 643 & 653 & 668 \\
\hline$n$ & 1948 & 1884 & 1941 & 2031 & 1991 & 1916 & 633 & 626 & 635 & 648 & 638 & 623 \\
\hline$R$ & 1977 & 1999 & 1940 & 1736 & 1765 & 1936 & 714 & 708 & 680 & 595 & 654 & 682 \\
\hline$\mu_{R}$ & 1940,0 & 1938,4 & 1940,0 & 1935,6 & 1938,6 & 1939,7 & 646,3 & 645,9 & 646,3 & 646,5 & 646,4 & 645,7 \\
\hline$\sigma_{R}$ & 31,132 & 31,108 & 31,133 & 31,063 & 31,110 & 31,128 & 17,952 & 17,942 & 17,954 & 17,958 & 17,956 & 17,936 \\
\hline Z & 1,190 & 1,947 & 0,000 & $-6,427 * *$ & $-5,580 * *$ & $-0,120$ & $3,774 * *$ & $3,461 * *$ & 1,875 & $-2,867 * *$ & 0,423 & $2,023^{*}$ \\
\hline$p$-value & 0,234 & 0,052 & 1,000 & 0,000 & 0,000 & 0,905 & 0,000 & 0,001 & 0,061 & 0,004 & 0,673 & 0,043 \\
\hline \multicolumn{13}{|c|}{ Panel C: positive/negative monthly returns defined relative to zero } \\
\hline$n_{+}$ & 113 & 115 & 110 & 99 & 106 & 109 & 43 & 42 & 39 & 41 & 42 & 38 \\
\hline$n$ & 66 & 64 & 69 & 80 & 73 & 70 & 16 & 17 & 20 & 18 & 17 & 21 \\
\hline$R$ & 83 & 79 & 89 & 80 & 62 & 84 & 22 & 22 & 28 & 21 & 19 & 25 \\
\hline$\mu_{R}$ & 84,3 & 83,2 & 85,8 & 89,5 & 87,5 & 86,3 & 24,3 & 25,2 & 27,4 & 26,0 & 25,2 & 28,1 \\
\hline$\sigma_{R}$ & 6,208 & 6,126 & 6,319 & 6,595 & 6,443 & 6,352 & 2,996 & 3,112 & 3,406 & 3,219 & 3,112 & 3,486 \\
\hline Z & $-0,214$ & $-0,691$ & 0,506 & $-1,439$ & $-3,951 * *$ & $-0,354$ & $-0,775$ & $-1,029$ & 0,164 & $-1,559$ & $-1,994 *$ & $-0,875$ \\
\hline$p$-value & 0,830 & 0,489 & 0,613 & 0,150 & 0,000 & 0,723 & 0,438 & 0,303 & 0,870 & 0,119 & 0,046 & 0,381 \\
\hline \multicolumn{13}{|c|}{ Panel D: positive/negative monthly returns defined relative to the mean return } \\
\hline$n_{+}$ & 100 & 101 & 96 & 88 & 91 & 96 & 35 & 35 & 31 & 34 & 33 & 34 \\
\hline$n$ & 79 & 78 & 83 & 91 & 88 & 83 & 24 & 24 & 28 & 25 & 26 & 25 \\
\hline$R$ & 91 & 79 & 91 & 74 & 66 & 88 & 27 & 26 & 29 & 31 & 23 & 27 \\
\hline$\mu_{R}$ & 89,3 & 89,0 & 90,0 & 90,5 & 90,5 & 90,0 & 29,5 & 29,5 & 30,4 & 29,8 & 30,1 & 29,8 \\
\hline$\sigma_{R}$ & 6,578 & 6,560 & 6,635 & 6,669 & 6,669 & 6,635 & 3,673 & 3,673 & 3,797 & 3,717 & 3,753 & 3,717 \\
\hline Z & 0,263 & $-1,528$ & 0,146 & $-2,470^{*}$ & $-3,670 * *$ & $-0,306$ & $-0,674$ & $-0,946$ & $-0,375$ & 0,319 & $-1,888$ & $-0,757$ \\
\hline$p$-value & 0,792 & 0,127 & 0,884 & 0,013 & 0,000 & 0,760 & 0,500 & 0,344 & 0,708 & 0,750 & 0,059 & 0,449 \\
\hline
\end{tabular}

Notes: The runs test tests for a statistically significant difference between the expected number of runs vs. the actual number of runs. A run is defined as sequence of successive price changes with the same sign. The null hypothesis is that the successive price changes are independent and random. In Panels A and C, we define as a positive/negative return any return above/below zero. In Panels B and D, we define as a positive/negative return any return above/below the mean return.

* Null hypothesis rejection significant at the 5\% level. ** Null hypothesis rejection significant at the $1 \%$ level.

\section{Unit Root Tests}

In our third test we compute the Augmented Dickey-Fuller statistic to test the null hypothesis of a unit-root in the stock market indexes. We show results is Table 4. 
TABLE 4

Augmented Dickey-Fuller tests for the stock market indexes: January 1993 to December 2007

\begin{tabular}{|c|c|c|c|c|c|c|}
\hline & France & Germany & UK & Greece & Portugal & Spain \\
\hline \multicolumn{7}{|c|}{ Daily Data } \\
\hline ADF test statistic & -1.4807 & -1.2899 & -1.5393 & -1.3055 & -1.4313 & -1.3221 \\
\hline$p$-value & 0.9021 & 0.9232 & 0.8839 & 0.8724 & 0.8296 & 0.9023 \\
\hline Included observations & 3875 & 3878 & 3872 & 3871 & 3869 & 3876 \\
\hline Number of lags & 3 & 0 & 6 & 7 & 10 & 3 \\
\hline \multicolumn{7}{|c|}{ Monthly Data } \\
\hline ADF test statistic & -1.3875 & -1.2179 & -1.4384 & -1.3907 & -1.7026 & -1.2519 \\
\hline$p$-value & 0.8616 & 0.9032 & 0.8664 & 0.8607 & 0.7463 & 0.8959 \\
\hline Included observations & 179 & 179 & 178 & 179 & 178 & 179 \\
\hline Number of lags & 0 & 0 & 1 & 0 & 1 & 0 \\
\hline
\end{tabular}

Notes: Augmented Dickey-Fuller statistics test the null hypothesis of a unit root in the stock price series. Failure to reject the null hypothesis means that the random walk hypothesis is not rejected. The number of lags included in the regression is determined by the Akaike Info Criterion.

* Null hypothesis rejection significant at the $5 \%$ level. ** Null hypothesis rejection significant at the $1 \%$ level.

The number of lagged variables was determined by the Akaike Info Criterion, from a maximum of 10 lags allowed. The results are very clearly in favor of the random walk hypothesis, as the null hypothesis of a unit-root is not rejected for any type of returns (daily monthly), any country or any period. Again, this evidence is consistent with similar findings by Worthington and Higgs (2004). In any case we have to be cautious about these results, as Liu and He (1991) show that unit root tests may not detect departures from a random walk.

Variance Ratio Tests

Lo and MacKinlay (1988) show that the variance ratio test is more powerful than the Dickey-Fuller unit root test, and Ayadi and Pyun (1994) also argue that the variance ratio has more appealing features than other procedures. Table 5 presents the results of the variance ratios tests for stock market indexes prices. In order to facilitate comparisons with the other studies, we adopt the common procedure of selecting lags 2, 4, 8 and 16. 


\section{TABLE 5}

Variance ratio tests for lags $2,4,8$ and 16 for daily and monthly data of the stock market indexes: January 1993 to December 2007

\begin{tabular}{|c|c|c|c|c|c|c|c|c|c|c|c|}
\hline & & Lag 2 & Lag 4 & Lag 8 & Lag 16 & $\begin{array}{c}\text { Chow- } \\
\text { Denning }\end{array}$ & Lag 2 & Lag 4 & Lag 8 & Lag 16 & $\begin{array}{l}\text { Chow- } \\
\text { Denning }\end{array}$ \\
\hline & & \multicolumn{5}{|c|}{ Daily Price Increments 1993-2007 } & \multicolumn{5}{|c|}{ Daily Price Increments 2003-2007 } \\
\hline \multirow[t]{3}{*}{ France } & $V R(q)$ & 1,005 & 0,952 & 0,857 & 0,796 & & 0,941 & 0,892 & 0,785 & 0,686 & \\
\hline & $Z(q)$ & $(0,303)$ & $(1,606)$ & $(3,020)^{* *}$ & $(2,891)^{* *}$ & & $(2,104) *$ & $(2,078) *$ & $(2,607) * *$ & $(2,559) * *$ & \\
\hline & $Z^{*}(q)$ & $(0,215)$ & $(1,125)$ & $(2,179)$ & $(1,989)$ & $(2,179)$ & $(1,601)$ & $(1,573)$ & $(2,065) *$ & $(1,955)^{*}$ & $(2,065)$ \\
\hline \multirow[t]{3}{*}{ Germany } & $V R(q)$ & 0,997 & 0,974 & $0,940^{*}$ & $0,921 *$ & & 0,954 & 0,976 & 0,893 & 0,825 & \\
\hline & $Z(q)$ & $(0,202)$ & $(0,863)$ & $(1,259)$ & $(1,112)$ & & $(1,641)$ & $(0,466)$ & $(1,297)$ & $(1,425)$ & \\
\hline & $Z^{*}(q)$ & $(0,144)$ & $(0,598)$ & $(0,891)$ & $(0,749)$ & $(0,891)$ & $(1,374)$ & $(0,390)$ & $(1,118)$ & $(1,175)$ & $(1,374)$ \\
\hline \multirow[t]{3}{*}{$U K$} & $V R(q)$ & 1,003 & 0,914 & 0,796 & 0,758 & & 0,903 & 0,854 & 0,763 & 0,647 & \\
\hline & $Z(q)$ & $(0,179)$ & $(2,878)^{* *}$ & $(4,288) * *$ & $(3,427)^{* *}$ & & $(3,479) * *$ & $(2,800) * *$ & $(2,876) * *$ & $(2,878) * *$ & \\
\hline & $Z^{*}(q)$ & $(0,124)$ & $(1,971)^{*}$ & $(3,030)^{* *}$ & $(2,331)^{* *}$ & $(3,030)^{* *}$ & $(2,130) *$ & $(1,774) *$ & $(1,912) *$ & $(1,890) *$ & $(2,130)$ \\
\hline \multirow[t]{3}{*}{ Greece } & $V R(q)$ & 1,155 & 1,219 & 1,209 & 1,102 & & 1,062 & 1,119 & 1,140 & 1,132 & \\
\hline & $Z(q)$ & $(9,682)^{* *}$ & $(7,293)^{* *}$ & $(4,391) * *$ & $(1,448)$ & & $(2,230) *$ & $(2,282) *$ & $(1,700) *$ & $(1,077)$ & \\
\hline & $Z^{*}(q)$ & $(4,469)^{* *}$ & $(3,164)^{* *}$ & $(2,063)^{*}$ & $(0,684)$ & $(4,469) * *$ & $(1,559)$ & $(1,497)$ & $(1,187)$ & $(0,737)$ & $(1,559)$ \\
\hline \multirow[t]{3}{*}{ Portugal } & $V R(q)$ & 1,130 & 1,214 & 1,310 & 1,491 & & 1,060 & 1,114 & 1,155 & 1,216 & \\
\hline & $Z(q)$ & $(8,074) * *$ & $(7,109) * *$ & $(6,530) * *$ & $(6,944) * *$ & & $(2,153) *$ & $(2,182) *$ & $(1,887) *$ & $(1,765) *$ & \\
\hline & $Z^{*}(q)$ & $(3,829) * *$ & $(3,496) * *$ & $(3,476) * *$ & $(3,626) * *$ & $(3,829) * *$ & $(1,420)$ & $(1,406)$ & $(1,235)$ & $(1,108)$ & $(1,420)$ \\
\hline \multirow[t]{4}{*}{ Spain } & $V R(q)$ & 1,024 & 0,985 & 0,943 & 0,971 & & 0,962 & 0,937 & 0,910 & 0,848 & \\
\hline & $Z(q)$ & $(1,508)$ & $(0,509)$ & $(1,199)$ & $(0,409)$ & & $(1,351)$ & $(1,213)$ & $(1,095)$ & $(1,238)$ & \\
\hline & $Z^{*}(q)$ & $(1,027)$ & $(0,345)$ & $(0,837)$ & $(0,274)$ & $(1,027)$ & $(0,961)$ & $(0,862)$ & $(0,810)$ & $(0,899)$ & $(0,961)$ \\
\hline & & \multicolumn{5}{|c|}{ Monthly Price Increments 1993-2007 } & \multicolumn{5}{|c|}{ Monthly Price Increments 2003-2007 } \\
\hline \multirow[t]{3}{*}{ France } & $V R(q)$ & 1,054 & 1,246 & 1,440 & 2,020 & & 0,944 & 0,714 & 0,384 & 0,346 & \\
\hline & $Z(q)$ & $(0,721)$ & $(1,761) *$ & $(1,989) *$ & $(3,100) * *$ & & $(0,428)$ & $(1,173)$ & $(1,599)$ & $(1,141)$ & \\
\hline & $Z^{*}(q)$ & $(0,585)$ & $(1,420)$ & $(1,687)^{*}$ & $(2,502) * *$ & $(2,502) *$ & $(0,491)$ & $(1,223)$ & $(1,557)$ & $(1,101)$ & $(1,557)$ \\
\hline \multirow[t]{3}{*}{ Germany } & $V R(q)$ & 1,095 & 1,250 & 1,378 & 1,724 & & 0,955 & 0,779 & 0,552 & 0,491 & \\
\hline & $Z(q)$ & $(1,268)$ & $(1,787) *$ & $(1,708) *$ & $(2,201) *$ & & $(0,347)$ & $(0,907)$ & $(1,164)$ & $(0,888)$ & \\
\hline & $Z^{*}(q)$ & $(0,906)$ & $(1,323)$ & $(1,409)$ & $(1,788) *$ & $(1,788)$ & $(0,339)$ & $(0,798)$ & $(1,088)$ & $(0,848)$ & $(1,088)$ \\
\hline \multirow[t]{3}{*}{$\boldsymbol{U} \boldsymbol{K}$} & $\operatorname{VR}(q)$ & 0,861 & 0,835 & 0,832 & 1,103 & & 0,885 & 0,564 & 0,308 & 0,254 & \\
\hline & $Z(q)$ & $(1,864) *$ & $(1,179)$ & $(0,758)$ & $(0,312)$ & & $(0,883)$ & $(1,792) *$ & $(1,797) *$ & $(1,301)$ & \\
\hline & $Z^{*}(q)$ & $(1,353)$ & $(0,904)$ & $(0,634)$ & $(0,262)$ & $(1,353)$ & $(0,934)$ & $(1,711) *$ & $(1,754) *$ & $(1,281)$ & $(1,754)$ \\
\hline \multirow[t]{3}{*}{ Greece } & $V R(q)$ & 1,059 & 1,209 & 1,437 & 1,911 & & 0,984 & 0,829 & 0,470 & 0,359 & \\
\hline & $Z(q)$ & $(0,785)$ & $(1,493)$ & $(1,978) *$ & $(2,769) * *$ & & $(0,124)$ & $(0,702)$ & $(1,375)$ & $(1,118)$ & \\
\hline & $Z^{*}(q)$ & $(0,535)$ & $(1,092)$ & $(1,527)$ & $(1,996) *$ & $(1,996)$ & $(0,134)$ & $(0,723)$ & $(1,484)$ & $(1,148)$ & $(1,484)$ \\
\hline \multirow[t]{3}{*}{ Portugal } & $V R(q)$ & 1,240 & 1,378 & 1,456 & 1,811 & & 1,287 & 1,066 & 0,873 & 0,910 & \\
\hline & $Z(q)$ & $(3,215) * *$ & $(2,704) * *$ & $(2,064) *$ & $(2,466) * *$ & & $(2,207) *$ & $(0,269)$ & $(0,330)$ & $(0,157)$ & \\
\hline & $Z^{*}(q)$ & $(1,749) *$ & $(1,531)$ & $(1,278)$ & $(1,615)$ & $(1,749)$ & $(1,755) *$ & $(0,213)$ & $(0,289)$ & $(0,145)$ & $(1,755)$ \\
\hline \multirow[t]{3}{*}{ Spain } & $V R(q)$ & 1,054 & 1,049 & 0,982 & 1,363 & & 0,882 & 0,767 & 0,506 & 0,467 & \\
\hline & $Z(q)$ & $(0,716)$ & $(0,348)$ & $(0,082)$ & $(1,102)$ & & $(0,906)$ & $(0,955)$ & $(1,284)$ & $(0,930)$ & \\
\hline & $Z^{*}(q)$ & $(0,584)$ & $(0,269)$ & $(0,070)$ & $(0,917)$ & $(0,917)$ & $(0,732)$ & $(0,828)$ & $(1,236)$ & $(0,892)$ & $(1,236)$ \\
\hline
\end{tabular}

Notes: Variance ratio tests for daily and monthly price increments. The variance ratios, $\operatorname{VR}(q)$, are reported in the first rows, and the variance-ratio test statistics, $Z(q)$ for homoskedastic increments and $Z^{*}(q)$ for heteroskedastic increments, are reported in parentheses. The null hypothesis is that the variance ratios equal one, which means that the stock index daily prices follow a random walk. We also show the Chow and Denning (1993) statistic, which tests all the $Z^{*}(q)$ together,

* Null hypothesis rejection significant at the $5 \%$ level. ** Null hypothesis rejection significant at the $1 \%$ level.

In the case of Greece and Portugal, all variance ratios of daily data are larger than unity, which indicates that the variances grow more than proportionally with time. This could be due to heteroskedasticity of stock index prices in some cases, but the $Z^{*}(q)$ statistic also 
shows robust results, which is additional proof of autocorrelation in the data. This evidence is weaker in the last five years of the sample.

All other countries show variance ratios less than unity, and in the case of the UK this behavior is so extreme that it also leads to a rejection of the null hypothesis of a random walk in daily prices. Globally, the evidence is more favorable to the random walk hypothesis in the last five years, as the Chow-Denning test does not reject that hypothesis, for any of the six countries.

The evidence against the random walk hypothesis is much weaker in the monthly data. Under the assumption of heteroskedasticity, which we deem more appropriate, the random walk hypothesis is only rejected for France, in the period 1993-2007.

\section{Conclusions}

Table 6 summarizes the results of all the tests performed.

TABLE 6

Summary of Test Results: Random Walk Hypothesis Rejected?

\begin{tabular}{|c|c|c|c|c|c|c|}
\hline & France & Germany & UK & Greece & Portugal & Spain \\
\hline \multicolumn{7}{|c|}{ Daily Data: 1993-2007 } \\
\hline \multicolumn{7}{|l|}{ Serial Correlation Tests } \\
\hline Lag 1 positive return & NO & NO & $\mathrm{NO}$ & YES & YES & YES \\
\hline B-P and L-B Statistic & NO & YES & YES & YES & YES & YES \\
\hline Runs Test & NO & NO & NO & YES & YES & NO \\
\hline Augmented Dickey-Fuller & NO & NO & NO & NO & NO & NO \\
\hline Variance Ratio Test & $\mathrm{NO}$ & NO & YES & YES & YES & $\mathrm{NO}$ \\
\hline \multicolumn{7}{|c|}{ Daily Data: 2003-2007 } \\
\hline \multicolumn{7}{|l|}{ Serial Correlation Tests } \\
\hline Lag 1 return significant & NO & NO & NO & YES & YES & NO \\
\hline B-P and L-B Statistic & NO & YES & YES & NO & YES & NO \\
\hline Runs Test & YES & YES & NO & YES & NO & YES \\
\hline Augmented Dickey-Fuller & NO & NO & $\mathrm{NO}$ & NO & NO & NO \\
\hline Variance Ratio Test & $\mathrm{NO}$ & NO & NO & NO & NO & NO \\
\hline \multicolumn{7}{|c|}{ Monthly Data: 1993-2007 } \\
\hline \multicolumn{7}{|l|}{ Serial Correlation Tests } \\
\hline Lag 1 return significant & $\mathrm{NO}$ & NO & NO & NO & YES & NO \\
\hline B-P and L-B Statistic & NO & NO & NO & NO & NO & NO \\
\hline Runs Test & NO & NO & NO & YES & YES & NO \\
\hline Augmented Dickey-Fuller & NO & NO & NO & $\mathrm{NO}$ & NO & NO \\
\hline Variance Ratio Test & YES & NO & $\mathrm{NO}$ & $\mathrm{NO}$ & $\mathrm{NO}$ & $\mathrm{NO}$ \\
\hline \multicolumn{7}{|c|}{ Monthly Data: $2003-2007$} \\
\hline \multicolumn{7}{|l|}{ Serial Correlation Tests } \\
\hline Lag 1 return significant & NO & NO & $\mathrm{NO}$ & NO & NO & NO \\
\hline B-P and L-B Statistic & YES & NO & NO & YES & NO & NO \\
\hline Runs Test & NO & NO & NO & NO & NO & NO \\
\hline Augmented Dickey-Fuller & NO & NO & NO & NO & NO & NO \\
\hline Variance Ratio Test & $\mathrm{NO}$ & $\mathrm{NO}$ & $\mathrm{NO}$ & $\mathrm{NO}$ & $\mathrm{NO}$ & $\mathrm{NO}$ \\
\hline
\end{tabular}


Apart from the ADF test, which is very clearly favorable to the random walk hypothesis, all other tests provide mixed evidence. Positive serial correlation has been very strong in daily returns, in the case of Greece and Portugal, but declining in the last five years. This evidence of persistency in prices is consistent with the findings of: (i) fewer runs than were expected and (ii) the variance ratios tend to grow with the time lag.

For France, Germany, UK and Spain, most of the evidence does not allow the rejection of the null hypothesis, thus favoring the random walk interpretation. In the case of France, the runs test fails due to an excessive number of runs in daily data and the variance ratio fails in monthly data. Germany, UK and Spain meet all random walk criteria, in monthly data.

\section{References}

Abraham, A., Seyyed, F. and Alsakran, S. "Testing the Random Behavior and Efficiency of the Gulf Stock Markets" The Financial Review, 37, 3, 2002, pp. 469-480.

Dias, J., Lopes, L., Martins, V. and Benzinho, J.. "Efficiency Tests in the Iberian Stock Markets", 2002, Available at SSRN: http://ssrn.com/abstract=599926.

Fama, E. "Efficient Capital Markets: A Review of Theory and Empirical Work" Journal of Finance, 25, 2, 1970, pp. 283-417.

Fama, E. and French, K. "Permanent and Temporary Components of Stock Prices" Journal of Political Economy, 96, 2, 1988, pp. 246-273.

Gama, P. "A Eficiência Fraca do Mercado de Acções Português: Evidência do Teste aos Rácio de Variância, da Investigação de Regularidades de Calendário e da Simulação de Regras de Transacção Mecânicas”, Revista de Mercados e Activos Financeiros, 1, 1, pp. 5-28.

Grieb, T. and Reyes, M. "Random Walk Tests for Latin American Equity Indexes and Individual Firms", Journal of Financial Research, 22, 4, 1999, pp. 371-383. 
Groenewold, N. and Ariff, M. "The Effects of De-Regulation on Share Market Efficiency in the AsiaPacific", International Economic Journal, 12, 4, 1999, pp. 23-47.

Huang, B. "Do Asian Stock Markets Follow Random Walks? Evidence from the Variance Ratio Test", Applied Financial Economics, 5, 4, pp. 251-256.

Liu, C. and He, J. "A Variance-Ratio Test of Random Walks in Foreign Exchange Rates”, Journal of Finance, 46, 2, p. 773-785.

Lo, A. and MacKinlay, A. "Stock Market Prices do not Follow Random Walks: Evidence from a Simple Specification Test", The Review of Financial Studies, 1, 1, 1988, pp. 41-66.

Ma, S. and Barnes, M. “Are China's Stock Markets Really Weak-form Efficient?”, Centre for International Economic Studies, Adelaide University, Discussion Paper 0119, May 2001.

MacKinnon, J. “Approximate Asymptotic Distribution Functions for Unit-Root and Cointegration Tests”, Journal of Business \& Economic Statistics, 12, 2, 1994, pp. 167-176.

Magnusson, M. and Wydick, B. "How Efficient are Africa's Emerging Stock Markets", Journal of Development Studies, 38, 4, 2002, pp. 141-156.

Panas, E. "The Behaviour of Athens Stock Prices", Applied Economics, 22, 12, 1990, pp. 1715-1727.

Smith, G., Jefferis, K. and Ryoo, H. "African Stock Markets: Multiple Variance Ratio Tests of Random Walks", Applied Financial Economics, 12, 4, 2002, pp. 475-484.

Smith, G. and Ryoo, H. "Variance Ratio Tests of the Random Walk Hypothesis for European Emerging Stock Markets", The European Journal of Finance, 9, 3, 2003, pp. 290-300.

Urrutia, J. "Tests of Random Walk and Market Efficiency for Latin American Emerging Markets", Journal of Financial Research, 18, 3, 1995, pp. 299-309.

Wheeler, F., Neale, B., Kowalski, T. and Letza S. "The Efficiency of the Warsaw Stock Exchange Stock Exchange: The First Few Years 1991-1996”, The Poznan University of Economics Review, 2, 2, 2002, pp. 37-56.

Worthington, A. and Higgs, H. "Random Walks and Market Efficiency in European Equity Markets", Global Journal of Finance and Economics, 1, 1, 2004, pp. 59-78. 